\title{
Fuel economy of multiple conditions self-adaptive tractors with hydro-mechanical CVT
}

\author{
Maohua Xiao ${ }^{1 *}$, Jing Zhao ${ }^{1}$, Yuewen Wang ${ }^{1}$, Haijun Zhang ${ }^{1}$, Zhixiong Lu$^{1}$, Weihua Wei ${ }^{2}$ \\ (1. College of Engineering, Nanjing Agricultural University, Nanjing 210031, China; \\ 2. College of Mechanical and Electronic Engineering, Nanjing Forestry University, Nanjing 210037, China)
}

\begin{abstract}
Fuel economy is one of the most important properties of wheeled tractors. To improve the fuel economy, it is necessary to improve the engine fuel economy and the tractive efficiency of the driving mechanism. By analyzing the fuel economy evaluation index of wheeled tractors, the correlation among the tractor specific fuel consumption, the engine effective specific fuel consumption and the tractive efficiency of the driving mechanism were clarified in this paper. A tractor with a new type of hydro-mechanical continuously variable transmission (HMCVT) was designed and its whole model was established too. On the basis of each module's simulation model, the binary speed ratio matching simulation model of the gearbox-engine system was obtained by the control system reconstruction, and the fuel economy simulation analysis of the wheeled tractor with HMCVT was carried out under the two typical working conditions of plowing and sowing. Compared with the current national standard, the fuel economy of the newly designed wheeled tractors with the power of $130 \mathrm{~kW}$ was $380 \mathrm{~g} /(\mathrm{kW} \cdot \mathrm{h})$, specific fuel consumption was reduced by $21.1 \%$. The results showed that the new tractor fuel economy was greatly improved. Further, automatic navigation technology can be combined with the self-adaptive tractors to adapt to different working conditions and achieve the optimal fuel economy, which can be applied in precision agriculture.
\end{abstract}

Keywords: high power wheeled tractor, self-adaptive tractor, HMCVT, fuel economy, navigation DOI: $10.25165 /$ j.ijabe.20181103.2158

Citation: Xiao M H, Zhao J, Wang Y W, Zhang H J, Lu Z X, Wei W H. Fuel economy of multiple conditions self-adaptive tractors with hydro-mechanical CVT. Int J Agric \& Biol Eng, 2018; 11(3): 102-109.

\section{Introduction}

Agricultural tractors are one of the machines in agricultural productions which have great importance. Obviously, the machine working efficiency shall be raised to increase efficiency of agricultural products. Due to the limitation of nonrenewable fossil energy sources, it is essential to optimize fuel consumption. Therefore, the study to improve the high power wheeled tractor's fuel economy to fit the needs of the new era is of great significance.

From the perspective of fuel economy, there are many methods for the gearbox and the tractor respectively. A new combined scheme hydro-mechanical continuously variable transmission had been proposed, which consisted of an integrated hydraulic torque converter, chain continuously variable transmission, reduction gear set and corresponding control institutional composition ${ }^{[1]}$. Pan et al. ${ }^{[2]}$ proposed a method based on the manual gearbox speed ratio optimization, and by comparing the ratio before optimization and after, it was found that the fuel consumption was improved by $1.83 \%$. Cai et al. ${ }^{[3]}$ proposed a shift guidance system based on the

Received date: $2016-09-27$ Accepted date: 2018-02-27

Biographies: Jing Zhao, MS candidate, research interest: computer vision, Email: 1031145106@qq.com; Yuewen Wang, MS candidate, research interest: tractor energy consumption, Email: 963586399@qq.com; Haijun Zhang, PhD candidate, Associate Professor, research interest: mechanical optimization design, Email: zhhj@njau.edu.cn; Zhixiong Lu, PhD candidate, Professor, research interest: vehicle electronic control technology, Email: luzx@njau.edu.cn; Weihua Wei, $\mathrm{PhD}$ candidate, Associate Professor, research interest: high-performance cutting technology, Email: whwei@ njfu.edu.cn.

*Corresponding author: Maohua Xiao, PhD, Associate Professor, research interests: intelligent agricultural machinery and equipment. College of Engineering, Nanjing Agricultural University, 40\# Dianjiangtai Road, Pukou District, Nanjing 210031, China. Tel: +86-13951756153, Fax: +86-25-58606580, Email: xiaomaohua@njau.edu.cn. best fuel economy. The system validity was verified, the results show that the system average fuel consumption is up to $8.6 \%$, and can make the fuel consumption level more stable.

Not only the gearbox, but also the fuel economy of its carrier has been widely studied. The theory behind tractor usage offered a sufficient number of scientifically grounded criteria that characterize agricultural power units with respect to their particular properties $^{[4]}$. One of these characteristic values was used most widely and, in the majority of cases ${ }^{[5]}$, it decided and determined the choice of a particular tractor-this being its engine power rating ${ }^{[6,7]}$. A method had been proposed in various papers for determining a tractor's minimum required operating mass ${ }^{[8]}$, this mass and its engine power rating related to the analysis of general power balance. A characteristic feature of this method was the due consideration given to the non-linear dependence of the power unit's running gear slip rate on the drawbar pull, which was delivered by it ${ }^{[9]}$.

In order to study the fuel economy of tractor under multiple operating conditions, many models have been established. Automobile fuel economy calculation model was established to simulate the fuel economy ${ }^{[10]}$. $\mathrm{Ji}^{[11]}$ invented an assessment method and fuel economy device, the assessment method include the establishment of multiple regression models. The invention can evaluate the automobile fuel economy according to the driving data information corresponding to the non-economic process of the automobile fuel. Zhou et al. ${ }^{[12]}$ established a transient fuel consumption model with "steady-state initial estimate + transient correction", and the slope economic optimization algorithm was obtained. At present, a visual basic program was developed to determine the optimum gear and throttle position on the basis of minimum fuel consumption per hectare for plowing, cultivating and harrowing operations. The program provides an intuitive 
interface by linking database such as tractor, tire and fuel consumption model, soil and operating conditions to predict the minimum fuel consumption of selected model ${ }^{[13]}$.

However, some models cannot fully consider the effects of many factors on economic performance. The vehicle main parameters influence on the fuel economy was analyzed, and its sensitivity was studied too. Further, a new evaluation method-the weighted average method was applied to calculate the automobile fuel consumption. Various factors affecting the car fuel consumption were taken into accounts, such as road conditions and load, which helps to form a more accurate fuel economy evaluation ${ }^{[14]}$. A study was conducted to investigate the effects of five control variables: ballast, tyre inflation pressure, transmission gear, engine speed, and workload on three fuel efficiency parameters: fuel consumption per work hour (FC), fuel consumption per tilled area (FCA) and specific volumetric fuel consumption (SVFC) ${ }^{[15]}$. For determination of traction properties of a wheeled tractor vehicle, it is essential to determine directions and values of power flow through the wheels. These in turn depend on the forces and moments applied to a given wheel as well as the type and condition of the ground under the whee ${ }^{[16]}$. Most previous researchers indicate that about $20 \%-55 \%$ of available tractor power is lost in the process of interaction between tires and soil surface. Vertical wheel loads and tire performance are parameters that play a significant role in controlling slip and fuel consumption of a tractor ${ }^{[17]}$. Based on the positive development process of vehicle products and the whole vehicle's performance integration technology, Gao et al. $^{[18]}$ established a new development process based on energy flow and performance integration technology.

Currently, the study on fuel economy is basically in the field of automobile, but the research on high power wheeled tractors is insufficient. In view of that, the study proposes the binary speed ratio matching simulation model of the gearbox-engine system to simulate the fuel economy of high power wheeled tractors.

\section{Fuel economy evaluation index of wheeled tractors}

The specific fuel consumption $\mathrm{g}_{T}$ is an indicator to evaluate the tractor fuel economy. It refers to the amount of fuel $(\mathrm{g} / \mathrm{kW} \cdot \mathrm{h})$ consumed by the traction power of per unit kilowatt hour when the tractor is operating. The equation is shown in Equation (1):

$$
g_{T}=\frac{G_{T}}{P_{T}} \times 10^{3}
$$

where, $G_{T}$ is the tractor hourly fuel consumption, $\mathrm{kg} / \mathrm{h} ; P_{T}$ is the hook traction power, $\mathrm{kW}$.

$$
G_{T}-G_{e}, P_{T}=P_{e} \eta_{T}
$$

where, $G_{e}$ is the engine hourly fuel consumption, $\mathrm{kg} / \mathrm{h} ; \eta_{T}$ is the tractor pulling efficiency.

$$
g_{T}=\frac{g_{e}}{\eta_{T}}
$$

where, $g_{e}$ is the engine effective fuel consumption rate, $\mathrm{g} / \mathrm{kW} \cdot \mathrm{h}$. It can be seen that the tractor specific fuel consumption is related to the engine effective fuel consumption and the tractive efficiency of the driving mechanism.

From the above analysis we can see that the tractor fuel economy depends on the engine fuel economy and the tractive efficiency of the driving mechanism. Therefore, in order to improve the tractor fuel economy, it is necessary to improve the engine fuel economy and the tractive efficiency of the driving mechanism.

\section{Research on wheeled tractor with HMCVT}

\subsection{Transmission scheme principle of HMCVT}

The HMCVT developed by our team is applied in the high power tractor. The selected engine is WP6T180E21 ${ }^{[19]}$, a kind of pressurized, cold, high-pressure common rail EFI engine. The universal features are shown in Figure 1. The figure shows that the maximum output of the diesel engine is $132.5 \mathrm{~kW}$, the idle speed is $750 \mathrm{r} / \mathrm{min}$, the rated speed is $2200 \mathrm{r} / \mathrm{min}$, the minimum fuel consumption is less than $204 \mathrm{~g} /(\mathrm{kW} \cdot \mathrm{h})$, and the optimal economic speed is about $1500 \mathrm{r} / \mathrm{min}$. According to the demand of low-speed heavy load under the plowing and other conditions, the minimum speed is designed to be $4 \mathrm{~km} / \mathrm{h}$ and the maximum speed of the tractor to be $20 \mathrm{~km} / \mathrm{h}$, taking into account the increasing speed of tractors in industrially developed countries ${ }^{[20]}$ as well as the growing trend in double function of the operating machinery and transport machinery. In general, tractors are used primarily for transportation above $20 \mathrm{~km} / \mathrm{h}$. Tractor speed of different operating modes is shown in Table 1. The rear axle main reduction transmission ratio is 3.7 , side reduction transmission ratio is 5.6. That is, the total transmission ratio of the rear axle is set at 20.72. The diameter of the drive wheel is $1835 \mathrm{~mm}$, and the dynamic outer diameter is converted to be $1716 \mathrm{~mm}$ in accord with 0.935 of the tire outer diameter ${ }^{[21]}$.

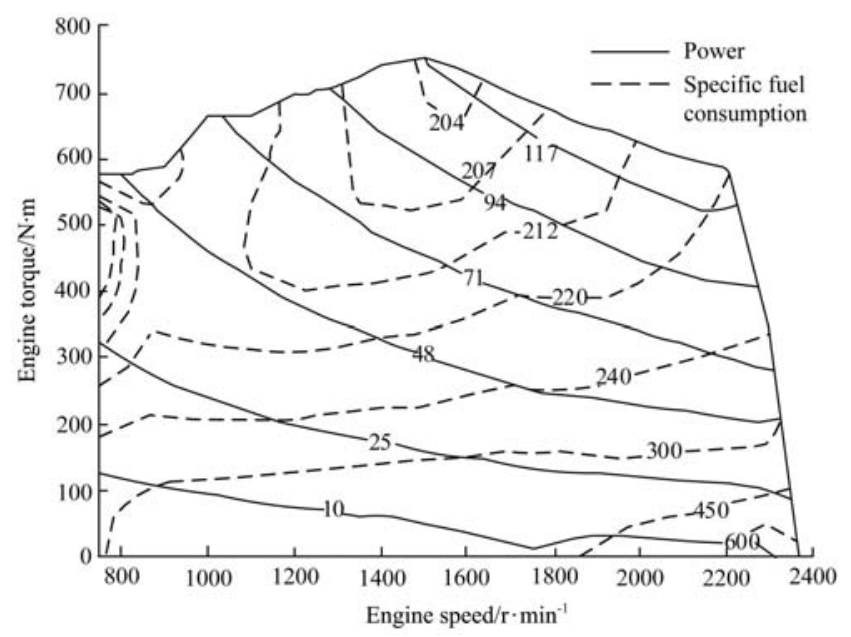

Figure 1 WP6T180E21 diesel engine universal features

Table 1 Tractor speed of different operating modes

\begin{tabular}{clc}
\hline \multicolumn{1}{c}{ Load } & \multicolumn{1}{c}{ Operation mode } & Speed $/ \mathrm{km} \cdot \mathrm{h}^{-1}$ \\
\hline \multirow{2}{*}{ Heavy load } & Plowing & $5-10$ \\
& Rotary tillage & $5-12$ \\
& Potato harvest & $4-8$ \\
\hline \multirow{5}{*}{ Medium load } & Pulverization & $3-12$ \\
& Intertillage and ripping & $4-14$ \\
& Harrowing & $4-13$ \\
& Front loading & $4-10$ \\
& Ridging & $4-12$ \\
\hline \multirow{2}{*}{ Light load } & Spraying & $6-12$ \\
& Mowing & $5-20$ \\
& Fertilizer spreading & $5-17$ \\
& Sowing & $6-15$ \\
\hline \multirow{2}{*}{ Transportation } & Postharvest surface & $6-12$ \\
& Substantial soil & $8-28$ \\
& Asphalt pavement & $12-48$ \\
\hline
\end{tabular}


The gearbox designed according to the above parameters is a four-stage double-row planetary convergent HMCVT, the driving principle is shown in Figure 2.

In the picture, gl-g12 is the gear pair, the transmission ratio is i1 - i12; P1, P2 is the planet row, the characteristic parameter is $\mathrm{k} 1$, $\mathrm{k} 2$; $\mathrm{c} 0-\mathrm{c} 5$ is the wet clutch, its bonding and separation controlled by the oil pressure. It can be seen from the figure, the engine power is divided into two steps after entering the gearbox: one goes through (when back driving is g1) gear pairs g2, g3 into the planets P1, P2; Another way is through the gear g4 into the line-motor volume control circuit, and through the motor shaft and gear g5 into the planets P1, P2. Two-way engine power converged at the planetary row P1, P2 and then differential output. As the mechanical transmission ratio is not adjustable, and the volume governor circuit transmission ratio can be adjusted by the swash plate angle of variable pump, it can make the entire gearbox speed change continuously with the variable pump displacement. After the two-row planetary confluence, the engine power output backward through the g6 to g9 gears, resulting in four stalls, called "section", each section of power output to the gearbox rear selectively through engagement and separation of $\mathrm{c} 1$ to $\mathrm{c} 4$ wet clutch.

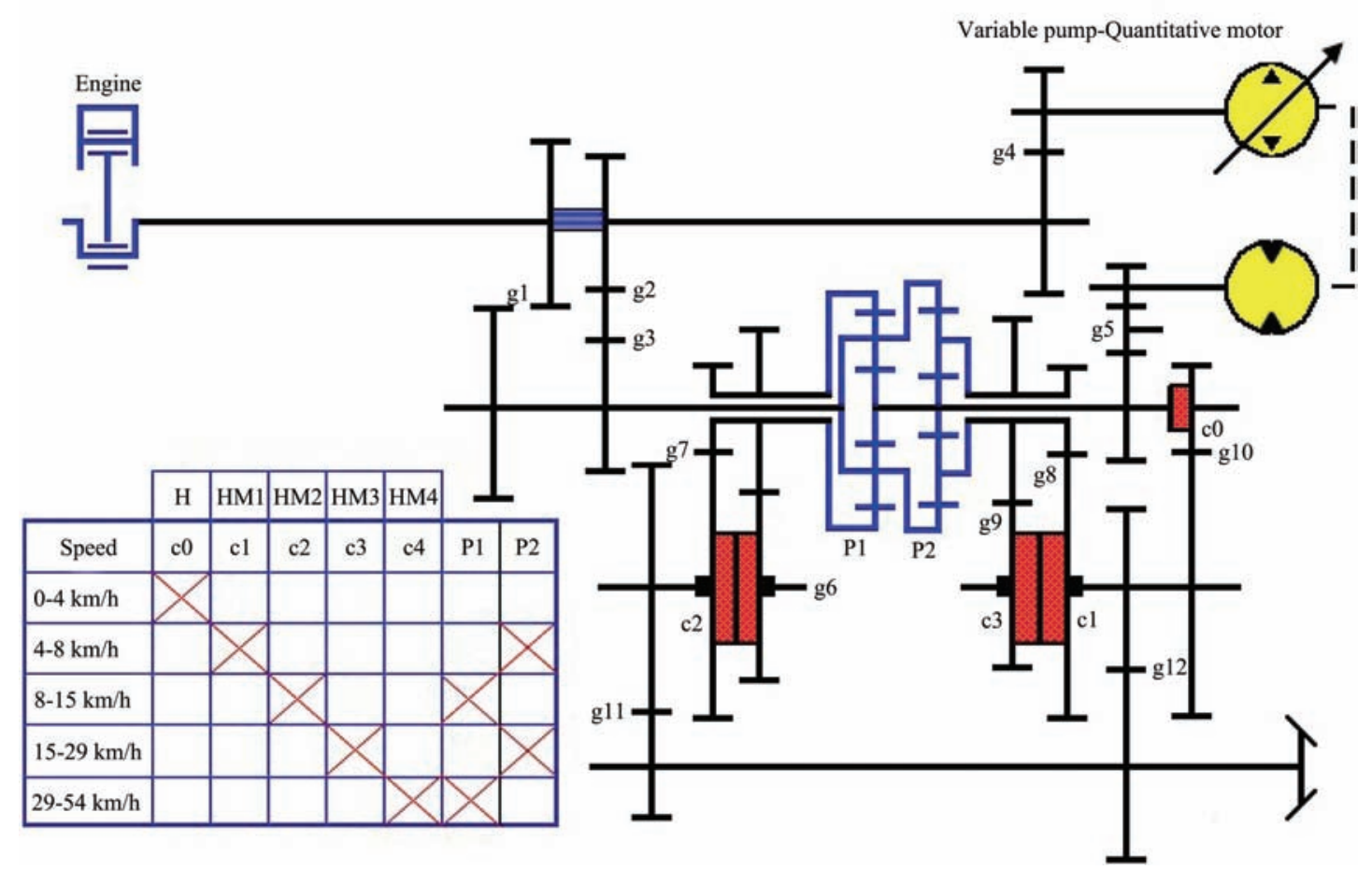

Figure 2 Transmission schematic diagram of the HMCVT

\subsection{Theoretical analysis and test of HMCVT regulation}

\subsubsection{Theoretical calculation}

By the planetary gear speed characteristic Equation (4), that is, the sun wheel speed is $n_{s}$, the gear ring speed is $n_{r}$, and the planet carrier speed is $n_{c}$, its characteristic parameter $k$ satisfy the following equation:

$$
n_{s}+k n_{r}-(1+k) n_{c}=0
$$

The planet carrier output speed $n_{c}$ is:

$$
n_{c}=\frac{n_{s}+k_{2} n_{r}}{1+k_{2}}=\frac{k_{2} i_{4} i_{5}-\varepsilon i_{2} i_{3}}{\left(1+k_{2}\right) i_{2} i_{3} i_{4} i_{5}}
$$

The rotational speed $n_{13}$ of the clutches $\mathrm{c} 1$ and $c_{3}$ is:

$$
n_{13}= \begin{cases}\frac{n_{c}}{-i_{8}}=-\frac{k_{2} i_{4} i_{5}-\varepsilon i_{2} i_{3}}{\left(1+k_{2}\right) i_{2} i_{3} i_{4} i_{5}} n_{e} & H M_{1} \\ \frac{n_{c}}{-i_{9}}=-\frac{k_{2} i_{4} i_{5}-\varepsilon i_{2} i_{3}}{k_{2} i_{4} i_{5}-\varepsilon i_{2} i_{3} i_{4} i_{5} i_{9}} n_{e} & H M_{2}\end{cases}
$$

The gearbox output shaft speed $n_{k}$ is:

$$
n_{k}= \begin{cases}\frac{n_{13}}{i_{12}}=\frac{k_{2} i_{4} i_{5}-\varepsilon i_{2} i_{3}}{\left(1+k_{2}\right) i_{2} i_{3} i_{4} i_{5} i_{8} i_{12}} n_{e} & H M_{1} \\ \frac{n_{13}}{i_{12}}=\frac{k_{2} i_{4} i_{5}-\varepsilon i_{2} i_{3}}{\left(1+k_{2}\right) i_{2} i_{3} i_{4} i_{5} i_{9} i_{12}} n_{e} & H M_{3}\end{cases}
$$

Similarly, gearbox output shaft speed HM2 and HM4 $n_{h}$ are:

$$
n_{h}= \begin{cases}\frac{n_{r}}{i_{7} i_{11}}=\frac{\left(1+k_{2}\right) i_{4} i_{5}+\varepsilon i_{2} i_{3}}{k_{1} i_{2} i_{3} i_{4} i_{5} i_{7} i_{11}} n_{e} & H M_{2} \\ \frac{n_{13}}{i_{12}}=\frac{\left(1+k_{1}\right) i_{4} i_{5}-\varepsilon i_{2} i_{3}}{k_{1} i_{2} i_{3} i_{4} i_{5} i_{6} i_{11}} n_{e} & H M_{4}\end{cases}
$$

When the engine speed is $750 \mathrm{r} / \mathrm{min}, 1000 \mathrm{r} / \mathrm{min}, 1500 \mathrm{r} / \mathrm{min}$, $1900 \mathrm{r} / \mathrm{min}, 2200 \mathrm{r} / \mathrm{min}$ respectively, the speed continuity of each section are calculated, the results are shown in Figure 3. It can be seen from the figure that the gearbox can be co-controlled by variable system displacement and clutch interruption control to achieve continuously output speed, and the output speed remains unchanged in the exchange before and after. To some extent, it is able to avoid the speed impact when changing sections and ensure the driving and riding comfort.

\subsubsection{Regulation test of HMCVT}

The HMCVT regulation feature is its most basic transmission characteristic, as shown in Figure 4. The tests are carried out respectively at $750 \mathrm{r} / \mathrm{min}, 1000 \mathrm{r} / \mathrm{min}, 1500 \mathrm{r} / \mathrm{min}, 1900 \mathrm{r} / \mathrm{min}$.

The gearbox speed is not affected by the engine speed and speed characteristics, but only affected by the pump-motor displacement ratio and the working section, so it is feasible to set the engine test speed at idle speed $750 \mathrm{r} / \mathrm{min}$. The test is carried out in the hydro-mechanical section. The test bench is shown in Figure 5. 


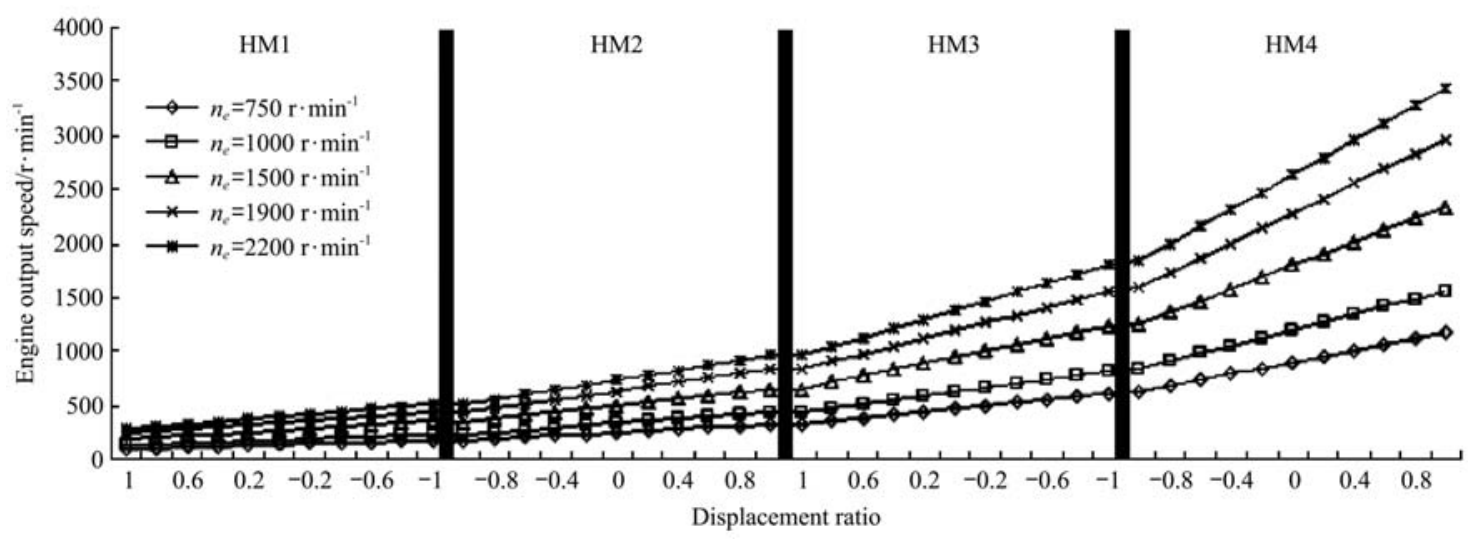

Figure 3 Speed characteristics of HMCVT under different input speed

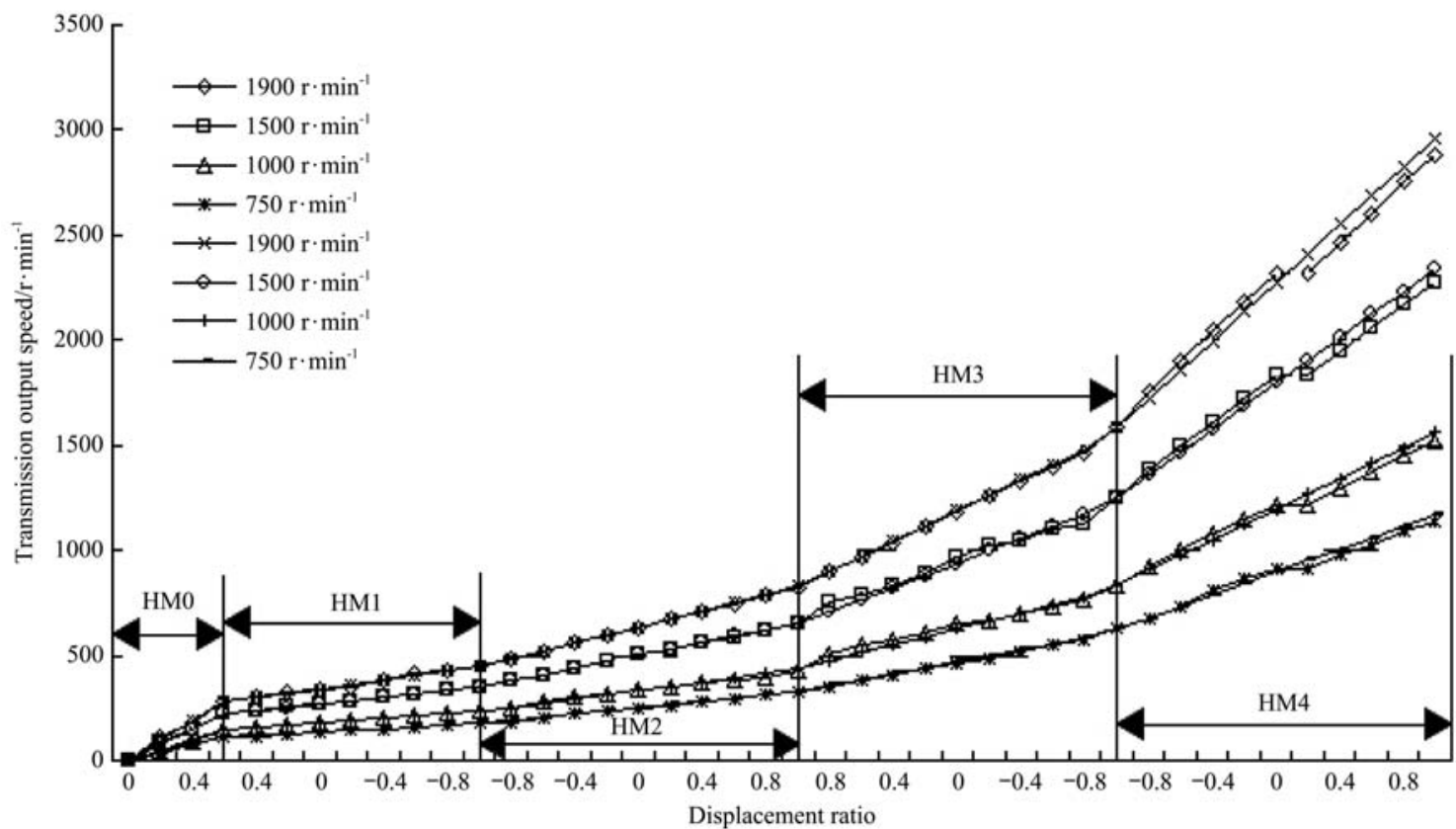

Figure 4 Test result of speed characteristics of the HMCVT ${ }^{[22]}$

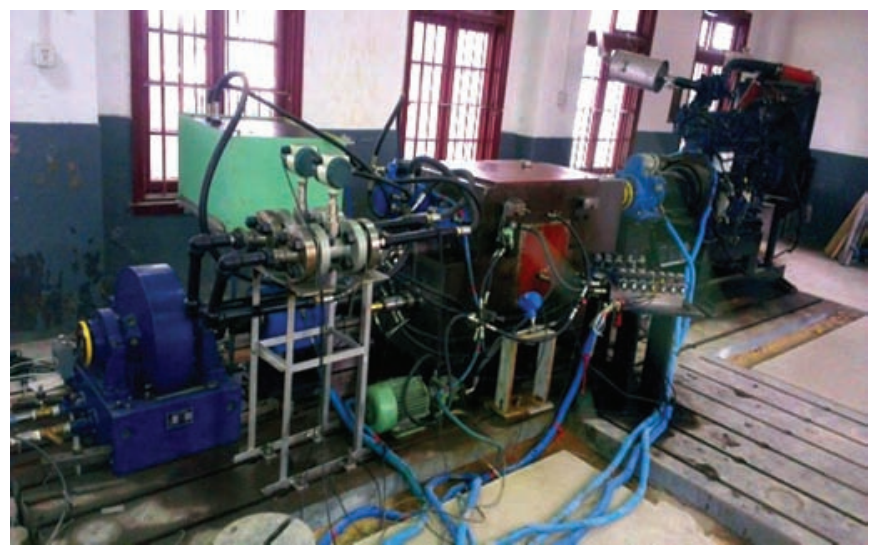

Figure 5 Test bench

The comparison between the data of experimental and theoretical is shown in Table 2. It is highly consistent between two data, therefore, the correctness and reliability of the gearbox design scheme are verified theoretically.

\section{Study on fuel economy of the self-adaptive wheeled tractor with HMCVT}

The speed ratio matching between HMCVT and engine system has been discussed. The purpose of speed ratio matching is to achieve the tractor fuel economy, therefore, the gearbox and the engine should be considered as a whole. Through the establishment of the mechanical model including the HMCVT, the simulation and analysis of binary ratio matching of the gearbox engine system, and the gearbox stepless regulation under the typical conditions of plowing and sowing is obtained to study the rationality of matching strategy. Considering the highly intelligent electronic control unit of gearbox, speed ratio matching is its core content. In practical work, the optimal speed ratio can be obtained by calculating the current operating conditions using navigation technology and sent it to the process controller, and then the tractor fuel economy can be achieved.

In the context of precision agriculture (PA), the application of autonomous navigation to agricultural vehicles for precision farming is regarded as a successful example, with drastic potential improvements in agricultural mechanization ${ }^{[23]}$. Automatic navigation for agricultural vehicles is one of the key technologies to realize precision farming operations, such as planting, fertilization, spraying, tillage, cultivation ${ }^{[24]}$. Applying the automatic navigation to the study can achieve better agricultural production. The combination makes it possible to feedback data to the controller under different operating conditions. The tractor immediately realizes variable speed to achieve the lowest fuel consumption rate. 
Table 2 Experimental data of transmission ratio characteristics of the HMCVT

\begin{tabular}{|c|c|c|c|}
\hline Gear & Displacement ratio & Experimental data & Theoretical data \\
\hline \multirow{5}{*}{ HM1 } & 1.00 & 7.93 & 7.99 \\
\hline & 0.35 & 3.40 & 3.22 \\
\hline & 0.00 & 5.56 & 5.56 \\
\hline & -0.39 & 4.97 & 4.98 \\
\hline & -1.00 & 4.28 & 4.27 \\
\hline \multirow{4}{*}{ HM2 } & -1.00 & 4.30 & 4.30 \\
\hline & -0.39 & 3.44 & 3.40 \\
\hline & 0.00 & 3.01 & 2.99 \\
\hline & 1.00 & 2.31 & 2.30 \\
\hline \multirow{3}{*}{ HM3 } & 1.00 & 2.29 & 2.29 \\
\hline & 0.00 & 1.60 & 1.60 \\
\hline & -1.00 & 1.23 & 1.22 \\
\hline \multirow{5}{*}{ HM4 } & -1.00 & 1.20 & 1.20 \\
\hline & -0.59 & 1.09 & 1.02 \\
\hline & 0.00 & 0.84 & 0.84 \\
\hline & 0.55 & 0.68 & 0.72 \\
\hline & 1.00 & 0.64 & 0.64 \\
\hline
\end{tabular}

\subsection{Construction of the simulation model}

In the Power Transmission library, a special four-stroke engine model is integrated. This model takes full account of the non-linearity of the combustion and compression processes during engine operation and the influence of the acceleration process, etc. It is clear that this model is very suitable for the study of engine dynamic characteristics. However, for this study, more attention is paid to its steady-state characteristics and the gearbox-engine matching problem. Therefore, using the existing library models directly may result in a large matching error. In order to solve this problem, the engine mathematical model has been build based on the engine characteristics and the most basic signal component library Signal Blocks, as shown in Figure 6.

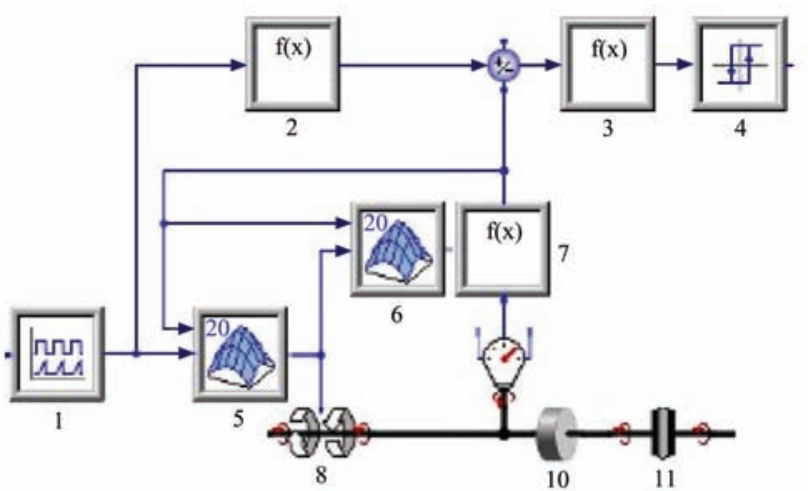

1. Engine oil opening signal 2-4. Matching output signal of gearbox, its composition concern with matching algorithm 5-6. Query tables of engine speed characteristics and fuel consumption characteristics 7. Engine speed conversion module, that can convert the speed unit of $\mathrm{rad} / \mathrm{s}$ into $\mathrm{r} / \mathrm{min} \quad 8$. Engine output torque signal 9. Engine output speed signal 10. Flywheel moment of inertia; 11. Coupling.

\section{Figure 6 Engine model}

Figure 7 shows the gearbox simulation model.

The construction of process controller model is a prerequisite for simulation and analysis. The study focus on the steady-state characteristics of the tractor before and after matching with operating conditions. There are requirements for the process control but do not care about the dynamic process, as long as it can achieve the basic autonomous adjustment function.

The control system model is shown in Figure 8.

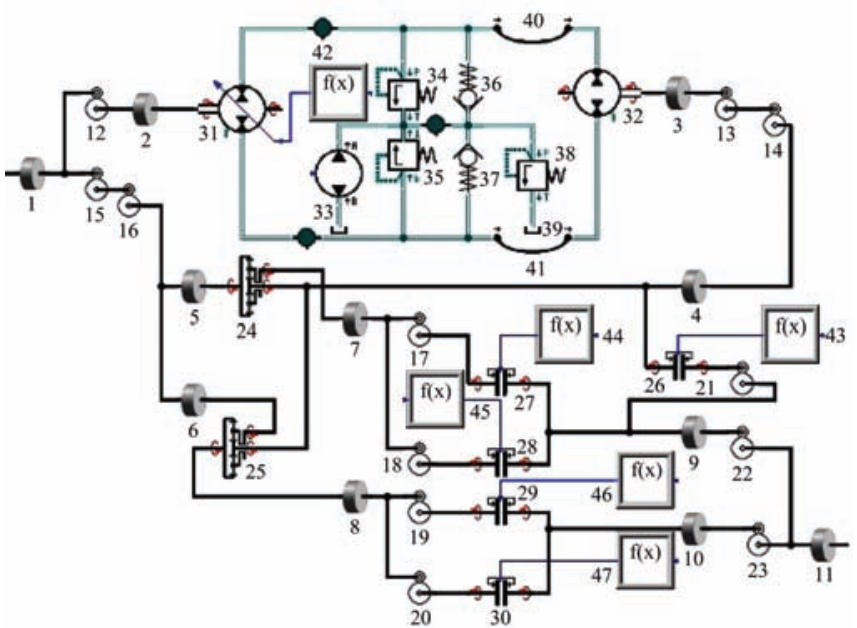

1-11. Rotary inertia of each axis 12-23. Gear pair 24-25. Planetary row 26-30. Wet clutch; 31. Variable system 32. Fixed displacement motor 33. Oil accumulation 34-35. Safety valve 36-37. One-way valve 38. Overflow valve 39. Fuel tank.

Figure 7 Simulation model of the HMCVT

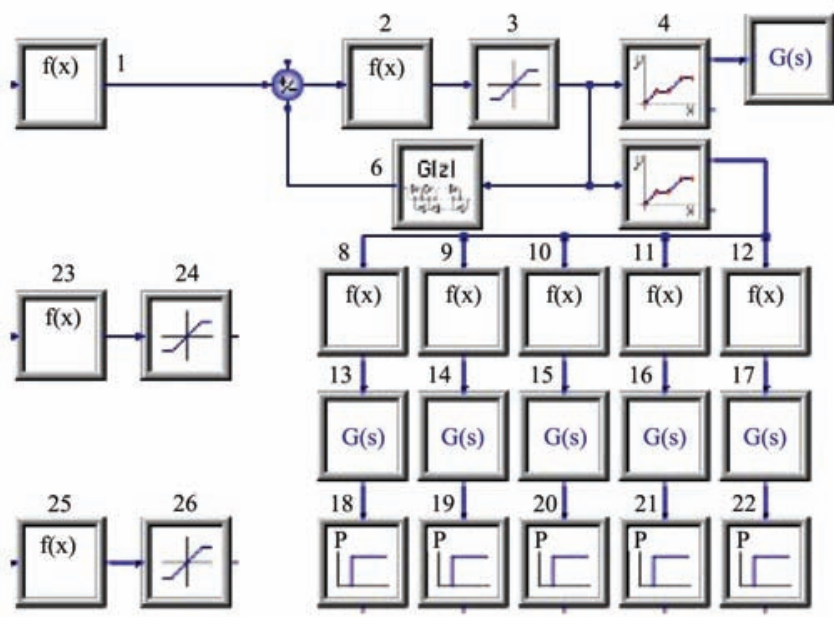

1. Ratio point signal of target speed, whose value depends on the matching strategy 2-3. Incremental calculation module and the output is +1 or -1 4-5. Variable poly displacement calculation module, the output is from -1 to +1 6. Transfer function $Z^{-1}$, for the feedback of the current speed ratio point 7 . is the point query table 8-12. Off Signal of clutch 13-17. Process transfer function 18-22. Oil conversion module 23-24. Speed ratio calculation module 25-26. Calculation module of systematized fuel consumption.

Figure 8 Process controller model of the HMCVT

On the basis of the above simulation models, the obtained binary speed ratio matching simulation model of the gearbox-engine system after the control system reconstruction is shown in Figure 9.

\subsection{Simulation analysis of plowing condition}

Under the condition of plowing, the tractor load is heavy the driving speed is limited to $5-10 \mathrm{~km} / \mathrm{h}$. In the simulation calculation, the used mouldboard plow width is $105 \mathrm{~cm}$, the mass is $1140 \mathrm{~kg}$, and the comprehensive friction coefficient between the plow and the soil is set as 0.4. The tractor starts with HM1. The initial target travel speed is $8 \mathrm{~km} / \mathrm{h}$, adjusts the speed to $5 \mathrm{~km} / \mathrm{h}$ at $200 \mathrm{~s}$, and adjusts the depth of plowing at $50 \mathrm{~s}, 100 \mathrm{~s}, 150 \mathrm{~s}, 250 \mathrm{~s}$, as shown in Table 3. The simulation lasts for $300 \mathrm{~s}$ and the results are shown in Figure 10. 


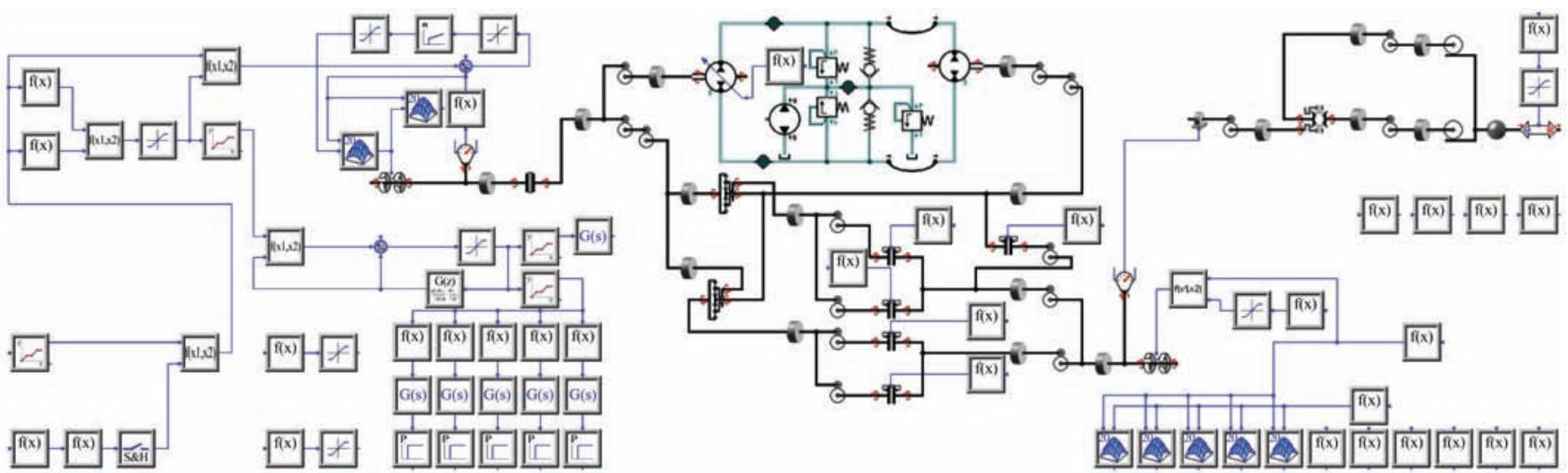

Figure 9 Tractor controller model in two-parameter speed match between transmission and engine

Table 3 Plowing simulation condition

\begin{tabular}{ccc}
\hline Time $/ \mathrm{s}$ & Target speed $/ \mathrm{km} \cdot \mathrm{h}^{-1}$ & Plowing depth $/ \mathrm{cm}$ \\
\hline $0-50$ & 8 & 16 \\
$50-100$ & 8 & 22 \\
$100-150$ & 8 & 27 \\
$150-200$ & 8 & 30 \\
$200-250$ & 5 & 30 \\
$250-300$ & 5 & 34 \\
\hline
\end{tabular}

The specific fuel consumption of engine and gearbox-engine system in the HM2 section can be as low as $203 \mathrm{~g} /(\mathrm{kW} \cdot \mathrm{h})$, $238 \mathrm{~g} /(\mathrm{kW} \cdot \mathrm{h})$. Respectively, in the HM1 section can be as low as $214 \mathrm{~g} /(\mathrm{kW} \cdot \mathrm{h}), 268 \mathrm{~g} /(\mathrm{kW} \cdot \mathrm{h})$. Under the controller's speed ratio adjustment, these values in the segment change a little with the load, the basic law is the greater the load, the better the economy. In addition, the gearbox economy in the HM2 section is better than the HM1 section, that is, the higher the segment, the better the fuel economy.

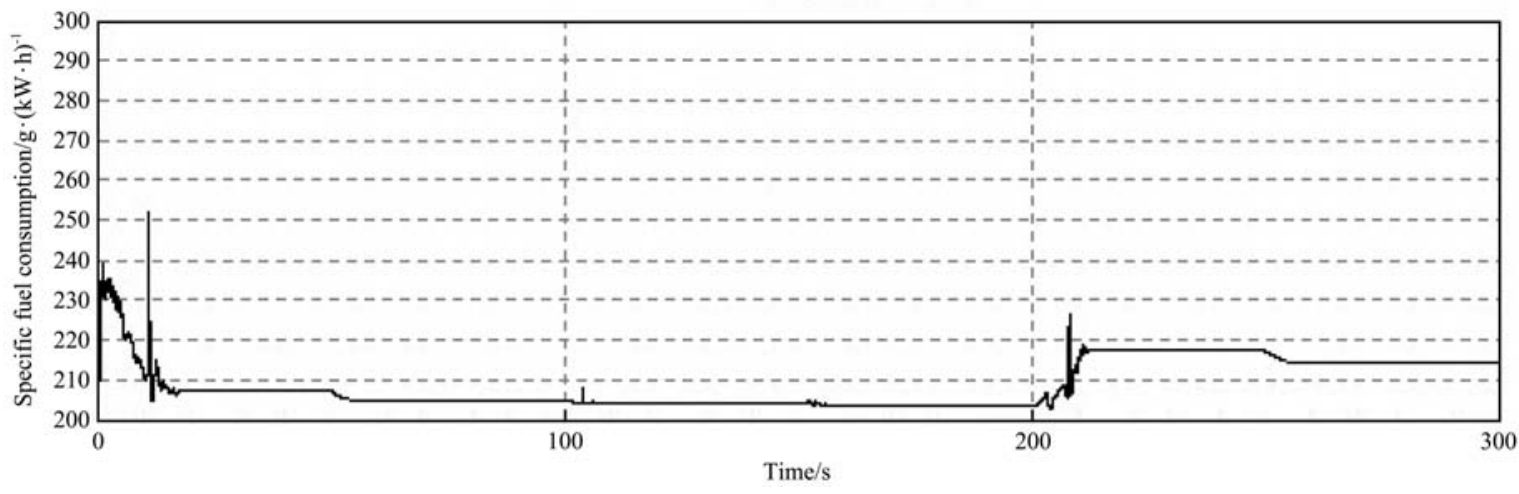

a. Engine specific fuel consumption

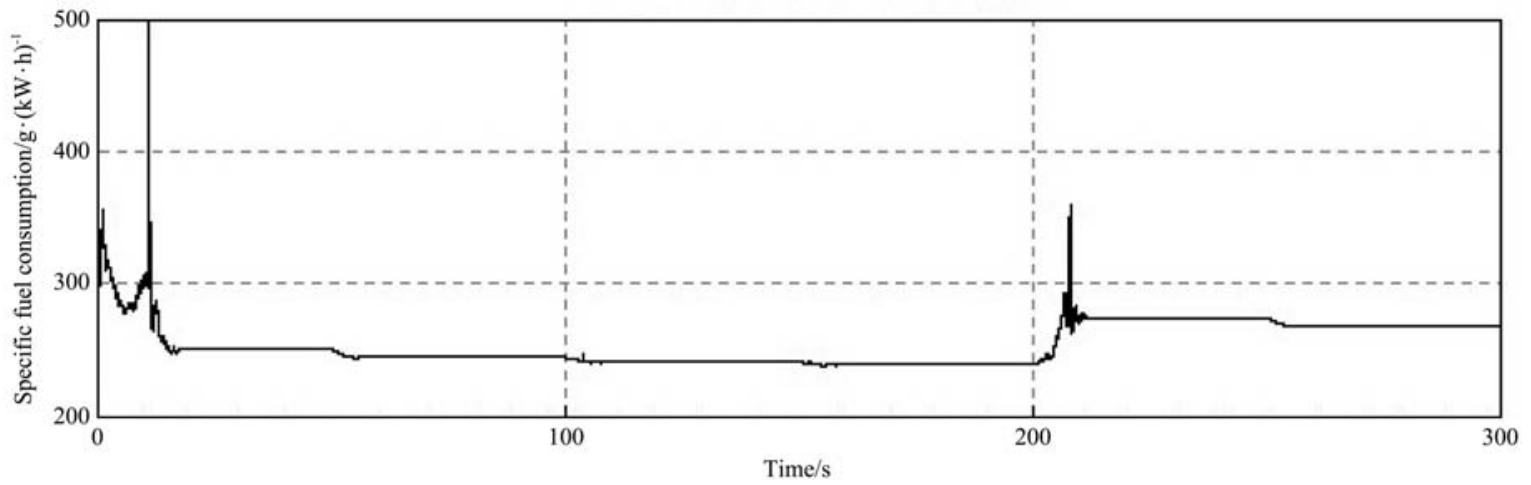

b. System specific fuel consumption

Figure 10 Simulation results in two-parameter speed match under plowing condition

\subsection{Simulation analysis of sowing condition}

Under the sowing condition of the tractor, the load is relatively light, the driving speed is limited to $6-15 \mathrm{~km} / \mathrm{h}$ and the small oil throttle is often used. In the simulation, set the resistance of unit width is $1500 \mathrm{~N}$, sowing range is $4 \mathrm{~m}$, and the tractor starts with HM1. Set the initial target speed is $8 \mathrm{~km} / \mathrm{h}$, in the first $50 \mathrm{~s}, 100 \mathrm{~s}$, the target speed is adjusted to $10 \mathrm{~km} / \mathrm{h}$ and $14 \mathrm{~km} / \mathrm{h}$, which is shown in Table 4. The simulation lasts for $150 \mathrm{~s}$ and the results are shown in Figure 11.

Table 4 Sowing simulation condition

\begin{tabular}{ccc}
\hline Time/s & Target speed $/ \mathrm{km} \cdot \mathrm{h}^{-1}$ & $\begin{array}{c}\text { Unit sowing amplitude } \\
\text { resistance/N }\end{array}$ \\
\hline $0-50$ & 8 & 1500 \\
$50-100$ & 10 & 1500 \\
$100-150$ & 14 & 1500 \\
\hline
\end{tabular}




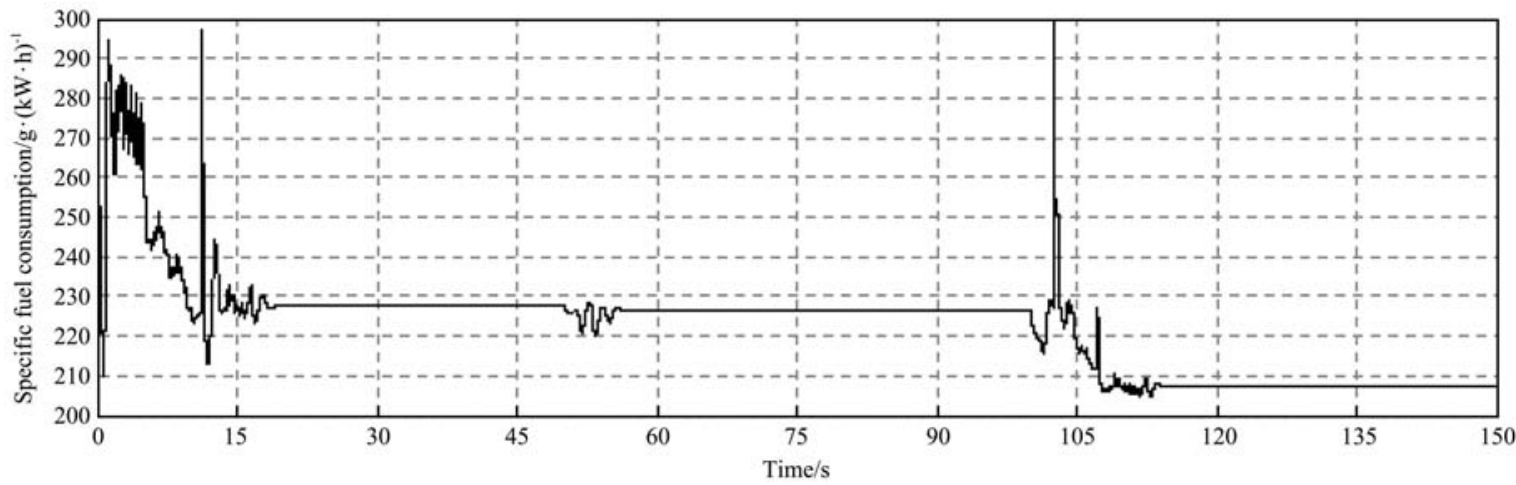

a. Engine specific fuel consumption

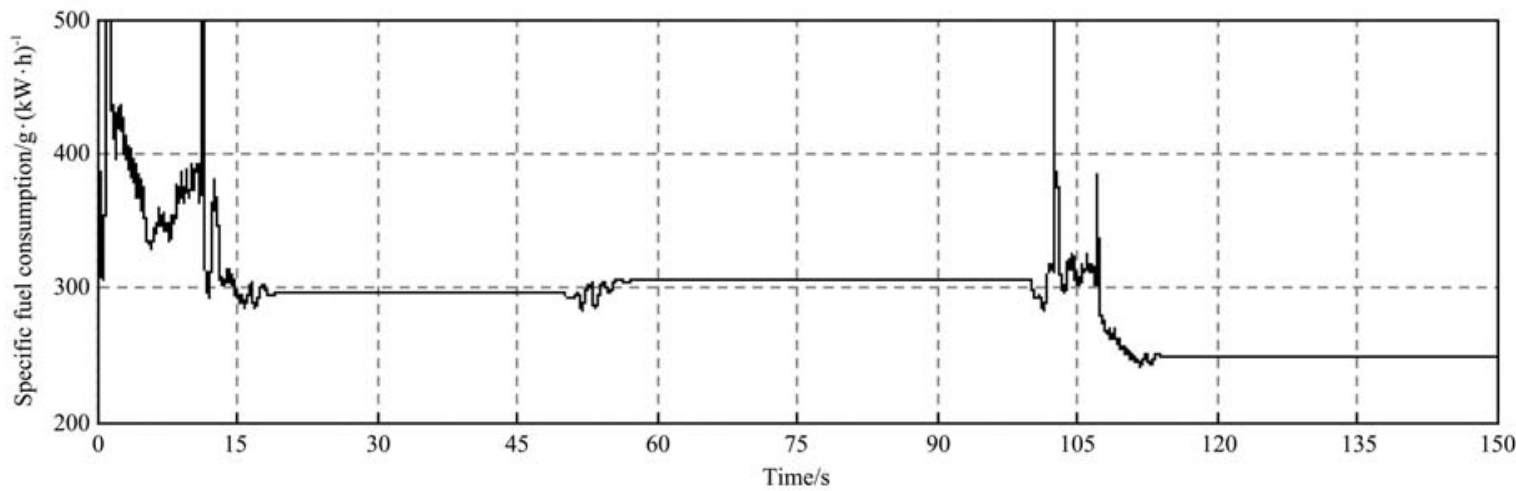

b. System specific fuel consumption

Figure 11 Simulation results in two-parameter speed match under sowing condition

The specific fuel consumption of engine and gearbox-engine system are maintained at a low level throughout the whole running process, in the HM2 section being as low as $226 \mathrm{~g} /(\mathrm{kW} \cdot \mathrm{h})$ and $296 \mathrm{~g} /(\mathrm{kW} \cdot \mathrm{h})$, in the HM3 section being as low as 207 and $248 \mathrm{~g} /(\mathrm{kW} \cdot \mathrm{h})$. Under the controller's speed ratio adjustment, the gearbox fuel economy in the HM3 section is better than the HM2 section, that is, the higher the segment, the better the fuel economy.

When working in the field, the situation is more complicated than in the bench test. The speed ratio matching strategy has strong adaptive ability for all kinds of complex working conditions, such as light load for sowing and heavy load for plowing. The whole machine economy of the "gearbox-engine" system in tractor field operation can be realized.The simulation results show that the speed ratio matching strategy is more sensitive to load traction. The greater the traction force, the better the economy of the speed ratio matching. It is particularly suitable for the situations of low speed and heavy load, such as tractor field operations under plowing and other conditions. Therefore, in the field, the fuel economy under plowing condition is better than that under sowing condition.

The above process can be monitored by a smartphone based application software (APP) named Precise Monitoring System (PMS). It can record the farm operation information including the tractor $^{[25]}$. The results showed that PMS can realize the basic functions such as precise and real-time monitoring.

\section{Conclusions}

In this study, a speed ratio matching method to achieve the tractor fuel economy was presented. Firstly, the stepless speed change function of HMCVT was realized by simulation and experimental verification based on the newly designed HMCVT program. Secondly, the study established simulation models of the engine, HMCVT and the control system. Then, on the basis of the above simulation models, the binary speed ratio matching simulation model of the gearbox-engine system was obtained. Finally, according to the combination of the automatic navigation and the HMCVT, the fuel economy under two typical working conditions of plowing and sowing were studied. Compared with the current national standard, the fuel economy of the wheeled tractors with the power of $130 \mathrm{~kW}$ is $380 \mathrm{~g} /(\mathrm{kW} \cdot \mathrm{h})$, specific fuel consumption is reduced by $21.1 \%$.

The combination of navigation and the economic performance of the multiple conditions self-adaptive tractor with the HMCVT has a very good application prospect in precision agriculture. Some improvements can be expected in the future. For example, for most of the farming operations mentioned, the navigation control accuracy of an agricultural vehicle navigation system can be improved further.

\section{Acknowledgments}

The research is funded partially by the National Key Research and Development Program of China (2016YFD0701103), Science and Technology Foundation of Outstanding Young Talents of Nanjing Agricultural University (YQ201605), the Fundamental Research Funds for the Central Universities fund (KYZ201760).

\section{[References]}

[1] Wang Y K, Chen J, Bai Y R. Research on tractor hydraulic mechanical continuously variable transmission. Transactions of the CSAE, 2000; 16(2): 75-79. (in Chinese)

[2] Pan W J, Zhu Y D, Jiang Z, Chen F Q, Mou Y J. Optimization of transmission speed ratio based on improved fuel economy. Equipment Manufacturing Technology, 2017; 4: 93-94. (in Chinese)

[3] Cai W X, Xiao C W, Huang X Y, Qiu Z C, Chen K. The shift guidance system based on the best fuel economy. Application of Computer 
Systems, 2015; 24(3): 270-274. (in Chinese)

[4] Moitzi G, Wagentristl H, Refenner K, Weingartmann H, Piringer G, Boxberger J. Effects of working depth and wheel slip on fuel consumption of selected tillage implements. Agricultural Engineering International: The CIGR e-journal, 2014; 16(1): 182-190.

[5] Cutini M, Bisaglia C. Development of a dynamometric vehicle to assess the drawbar performance of high-powered agricultural tractors. Journal of Terramechanics, 2016; 65: 73-84.

[6] T, Šmerda, J, Čupera. Tire inflation and its influence on drawbar characteristics and performance-Energetic indicators of a tractor test. Journal of Terramechanics, 2010; 47(6): 395-400.

[7] Turker U, Ergul I, Eroglu M C. Energy efficiency classification of agricultural tractors in Turkey based on OECD tests. Energy Education Science and Technology. Part A: Energy Science and Research, 2010; 28(2): 917-924.

[8] Godwin R J. A review of the effect of implement geometry on soil failure and implement forces. Soil and Tillage Research, 2007; 97(2): 331-340.

[9] Adamchuk V, Bulgakov V, Nadykto V. Theoretical research into the power and energy performance of agricultural tractors. Agronomy Research, 2016; 14(5): 1511-1518.

[10] Kang C F, Han H Q, Dai L Q, Zou L H. Fuel economy simulation of automobile and analysis of influencing factors. CHINA SAE, 2013; 4. (in Chinese)

[11] Ji Z. Evaluation method and device for fuel economy of automobile. Neusoft Group Co., Ltd, 2016. (in Chinese)

[12] Zhou M. Research on fuel economy of automatic variable speed vehicle ramp. Beijing Institute of Technology, 2016. (in Chinese)

[13] Kumar N, Pandey K P. A visual basic program for predicting optimum gear and throttle position for best fuel economy for $32 \mathrm{~kW}$ tractor. Computers and Electronics in Agriculture, 2015; 119: 217-227.
[14] Deng Z Y. Research on evaluation method of automobile fuel economy. Southwest Jiaotong University, 2015. (in Chinese)

[15] Lee J W., Kim J S, Kim K U. Computer simulations to maximise fue efficiency and work performance of agricultural tractors in rotovating and ploughing operations. Biosystems Engineering, 2016; 142: 1-11.

[16] Nadykto V. Method of determining agricultural tractor's engine power rating. Machinery and Technologies of Agro-Industry, 2014; 1:7-9.

[17] Algirdas J, Vidas D, Gediminas P. Effect of variations in front wheels driving lead on performance of a farm tractor with mechanical front-wheel-drive. Journal of Terramechanics, 2018; 77:23-30.

[18] Gao X H. Research on key technology of car fuel economy development. Hefei University of Technology, 2016. (in Chinese)

[19] Weichai Power Co., Ltd.. 180PS with Tractor Diesel Engine Development Test Report (Economic Edition). Weifang: Weichai Power Co., Ltd. 2010. (in Chinese)

[20] Zhu S H. Development and trend of tractor in Germany. Journal of Agricultural Mechanization, 2002; 33(1): 111-114. (in Chinese)

[21] Shi J L. Design of HMCVT for non-road vehicle and control of variable pump. Nanjing: Nanjing Agricultural University, 2011. (in Chinese)

[22] Ni X D. Research on transmission characteristics of tractor's hydraulic machinery multi-section double-row discharge continuously variable transmission. Nanjing: Nanjing Agricultural University, 2013. (in Chinese)

[23] Han X, Kim H J, Jeon C W, Moon H C, Kim J H. Development of a low-cost GPS/INS integrated system for tractor automatic navigation. Int J Agric \& Biol Eng, 2017; 10(2): 123-131.

[24] $\mathrm{Hu} \mathrm{J} \mathrm{T}$, Li T C. Cascaded navigation control for agricultural vehicles tracking straight paths. Int J Agric \& Biol Eng, 2014; 7(1): 36-44.

[25] Wu C C, Zhou L, Wang J, Cai Y P. Smartphone based precise monitoring method for farm operation. Int J Agric \& Biol Eng, 2016; 9(3): 111-121. 